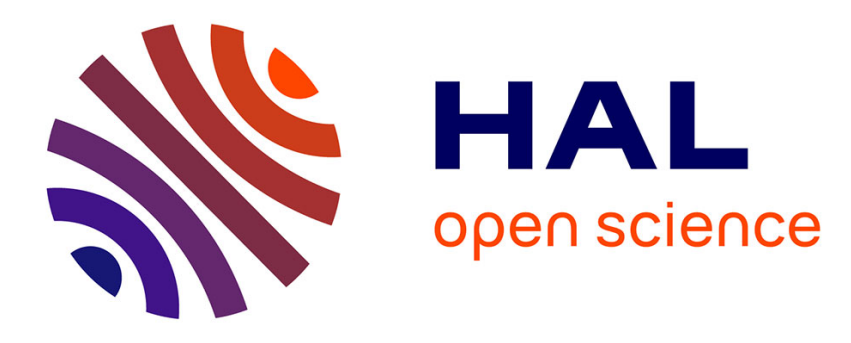

\title{
Nonlinear acoustical properties of suspended sediment
}

\author{
I. Kozhevnikova, L. Bjørnø
}

\section{To cite this version:}

I. Kozhevnikova, L. Bjørnø. Nonlinear acoustical properties of suspended sediment. Journal de Physique IV Proceedings, 1994, 04 (C5), pp.C5-1145-C5-1148. 10.1051/jp4:19945253 . jpa-00252942

\section{HAL Id: jpa-00252942 https://hal.science/jpa-00252942}

Submitted on 1 Jan 1994

HAL is a multi-disciplinary open access archive for the deposit and dissemination of scientific research documents, whether they are published or not. The documents may come from teaching and research institutions in France or abroad, or from public or private research centers.
L'archive ouverte pluridisciplinaire HAL, est destinée au dépôt et à la diffusion de documents scientifiques de niveau recherche, publiés ou non, émanant des établissements d'enseignement et de recherche français ou étrangers, des laboratoires publics ou privés. 


\title{
Nonlinear acoustical properties of suspended sediment
}

\author{
I.N. KOZHEVNIKOVA and L. BJøRNØ \\ Technical University of Denmark, Department of Industrial Acoustics, Building 425, 2800 Lyngby, \\ Denmark
}

\begin{abstract}
Maritime advances during recent years have shown the importance of and the need for development of ultrasonic methods for the investigation of the transport of suspended marine sediments in rivers and in coastal regions. Two main acoustical procedures have been developed and used for the investigations of suspended sediment qualities during the laboratory studies, (1) high frequency resonance backscattering and (2) attenuation acoustic spectroscopy. Both approaches are based on the same fundamental concepts, the interaction process between ultrasonic signals and suspended sediment particles. On this background a comprehensive study has been launched by the EC under the MAST Programme aiming at a characterization of suspended matter by acoustic remote sensing technique. The results of the initial theoretical studies of nonlinear properties of the suspended sediments are reported.
\end{abstract}

\section{INTRODUCTION}

There is a great need for reliable measurements of the concentrations and particle size distributions of suspended sediments in field studies, in particular along coasts and in estuaries. these measurements are also it is relevant to the detection of pollution, since pollutants tend to be very small suspended particles with a size of $20-30 \mu \mathrm{m}$. The use of acoustical methods for the estimation of suspended sediment concentration in the ocean has been suggested long time ago [1]. Only little has been done for many years, but progress has been made over the last decade through theoretical as well as experimental studies [2-4]. Although these studies have demonstrated the potential of acoustic remote sensing techniques for sediment transport studies, several difficulties still remain, particular in relation to a proper choice of the most adequate model for the suspended sediment particles. Such a model is needed for the correct interpretation of the experimental results.

\section{CHARACTERISTICS OF SUSPENDED SEDIMENT PARTICLES}

In natural condition in the ocean, close to the seabed, suspended sediments form the thin layer of several tenth of $\mathrm{cm}$ from the bottom consisting of different groups of particles with different physical properties. They comprise: silt, mud, clay and sand with an average size distribution between $5 \mu \mathrm{m}$ and $1 \mathrm{~mm}$. Laboratory studies of ocean sediments by optical technique have shown the irregular shape of the particles. For sand samples it was found that in average the most probable shape is an elliptical one. The size distribution for suspended sand ranges between $80 \mu \mathrm{m}$ and $1 \mathrm{~mm}$. For clay particles the typical size distribution is from $10 \mu \mathrm{m}$ up to $100 \mu \mathrm{m}$. Micro photographs of clay samples 
have shown a plate-like shape of the particles with a thickness of a few micrometers and dominating length size $10-20 \mu \mathrm{m}$ [4]. This shape is closely related to the crystal structure. Silt has the smallest size of the particles in suspended sediments. Usually, the size of the silt particles ranges from $1 \mu \mathrm{m}$ to $50 \mu \mathrm{m}$.

Another important characteristic feature of sediments is sediment concentration. Two different approaches exist in suspended sediment modelling studies: Low concentration of sediments $(<0.1$ $\left.\mathrm{kg} / \mathrm{m}^{3}\right)$, and high concentration of sediments $\left(<10 \mathrm{~kg} / \mathrm{m}^{3}\right)$. For the second model, i.e. high concentration of sediments, the effects of multiple scattering, flocculation and nonlinear effects should be taken into consideration.

\section{EXPERIMENTAL METHODS FOR SUSPENDED SEDIMENT STUDIES}

Two main methods were developed for investigation of suspended sediment qualities. They are: Laser optical method, and high frequency ultrasonic method. Optical methods are based on investigation of scattering, transmission and extinction of laser pulse signals through suspended sediment flow, and this method is useful for, at least, partially transparent media [5]. Another restriction for the application of optical method arises from high sensitivity of this method to the size of suspended particles. This is due to the fact, that the wavelength of light is small compared to all relevant particles sizes. Therefore, optical methods operate in the geometrical range of scattering.

Two alternative, ultrasonic based methods have been developed recently for sediment transportation studies. Acoustic (back)scattering [6-8] and attenuation spectroscopy [4]. It is well known, that the level of the scattered signal amplitude depends on the size, the number, the shape (surface topography) and the elastic properties of the scatterers and, therefore, can be used for definition of parameters of suspended particles. In the case of attenuation spectroscopy the same parameters (size, number, shape and elasticity) influence the attenuation spectra of ultrasonic signals propagating in suspensions of sediments, because in this case the attenuation is mostly due to scattering. The weak side of attenuation spectroscopic methods is, that at present this method is, in fact, an empirical method.

\section{ACOUSTIC NONLINEARITY OF SUSPENDED SEDIMENTS}

\subsection{Theoretical background}

Suspensions of particles in water form a liquid-solid two-phase medium, which could show nonlinear properties [9]. According to the theory [10], the effective nonlinear parameter B/A of a mixture was found to be:

$$
\frac{B}{A}=\frac{1}{\xi_{s}^{2}} \Sigma \xi_{i}^{2}\left(\frac{B}{A}\right)_{i} C_{i}
$$

where $C_{i}$ is the volume fraction of $i$ 'th components, $(B / A)_{i}$ is the nonlinear parameter of the $i^{\prime}$ th components, and $\xi_{\mathrm{s}}$ is the effective adiabatic compressibility:

$$
\xi_{s}=\Sigma \xi_{i} C_{i}
$$

The magnitude of the B/A ratio, which for most biological media is between 5 and 11, indicates the ability of the media to form higher harmonics to an original sinusoidal wave of finite amplitude during its propagation away from the wave source. 


\subsection{Methods of measurement of $\mathrm{B} / \mathrm{A}$}

Among many well developed procedures for determination of B/A in liquid, the finite amplitude method and the thermodynamic method [9] have in particular been used in practice. The first method, which has been chosen for the investigation of the nonlinearity of the suspended in water sediment, gives the dependence of the second harmonic pressure amplitude $\mathrm{P}_{2}$ on the propagation distance $\mathrm{x}$ from the sound source for the case of plane wave incidence. For the propagation of ultrasound through the suspensions of sediments the attenuation play an important role [10]. In this case the nonlinear parameter $\mathrm{B} / \mathrm{A}$ can be determined using the following expression:

$$
P_{2}=\frac{\left(2+\frac{B}{A}\right) P_{0}^{2} \omega}{2 \rho c^{3}} \frac{e^{-2 \alpha_{1} x}-e^{-\alpha_{2} x}}{\alpha_{2}-2 \alpha_{1}}
$$

where $\alpha_{1,2}$ are the attenuations coefficients for the fundamental and its second harmonic amplitude, $\omega$ is the fundamental frequency, $\rho$ is the medium density, and $c$ is the sound speed in mixture water and sediment. Attenuation for this two phase medium is the function of frequency and concentration for the constant temperature:

$$
\alpha(\omega)=\left(2,06 \cdot 10^{-13}+7 \cdot 10^{-10} C\right) \cdot \omega^{2}
$$

Sound speed $\mathrm{c}$ in the mixture will be the function of the concentration of the suspended sediment $\mathrm{C}$ and can be calculated using the Wood's theory. Fig. 1 shows this dependence for relatively low sediment concentrations.

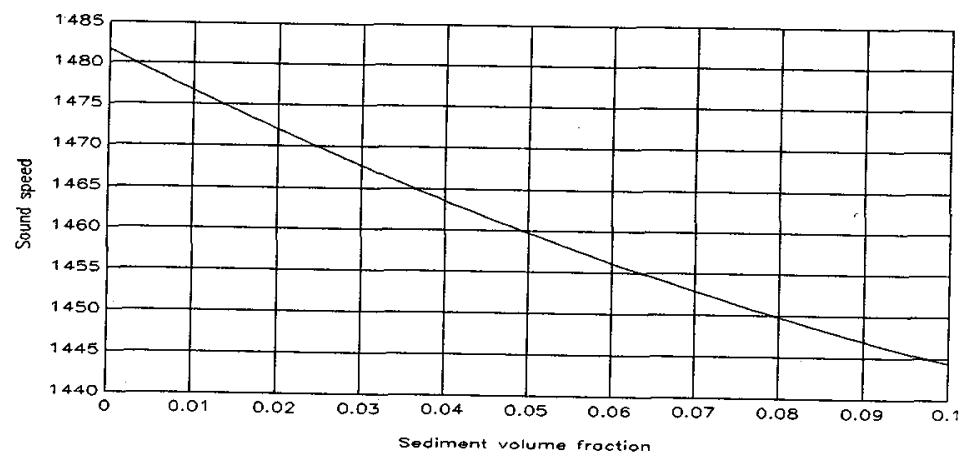

Figure 1. Sound speed as a function of sediment concentration.

The advantage of the second, thermodynamic method, is that this method does not dependent on the characteristics of the ultrasonic field, but experimental realization is more complicated.

\subsection{Acoustic nonlinearity of water comprising suspended sediment and air bubbles}

In general, suspensions of marine sediments in the sea comprise only $0.1 \%-0.5 \%$ of volume concentration of solid. That is why the nonlinear properties of suspended marine sediments mostly arise from the nonlinear properties of water. The acoustic nonlinear parameter of water shows strong dependence on temperature: The B/A value increases by about $50 \%$ when the temperature increases from $0{ }^{\circ} \mathrm{C}$ to $100^{\circ} \mathrm{C}$ [11]. For the temperature of $20^{\circ} \mathrm{C}$ the experimental value of $\mathrm{B} / \mathrm{A}$ is about 5 . But this parameter could be changed dramatically by the presence of air bubbles, which are always found in water as small microbubbles in very low concentrations (with the sizes around a few $\mu \mathrm{m}$ and volume concentration $10^{-8}-10^{-10}$ ). The effective nonlinear parameter $\mathrm{B} / \mathrm{A}$ of a bubbly medium is a 
strong function of the gas volume fraction: $B / A$ reaches the maximum value of about $9 \times 10^{3}$ near the volume fraction of $6 \times 10^{-5}$ at $20^{\circ} \mathrm{C}$, and than falls to the air value of $\mathrm{B} / \mathrm{A}$ of about $0.4[12,13]$.

For the above mentioned reasons, a measurement of the effective nonlinear parameter B/A in marine sediments suspended in water will comprise several steps:

1. Experimental studies of the nonlinear parameter B/A of water without sediments and under known initial conditions;

2. Experimental studies of the nonlinear parameter of the sediments suspended in water sediments for different concentration values (verification of the theoretical model based on expression (1)).

\section{CONCLUSIONS}

The need for fundamental physical knowledge regarding interaction processes between acoustic waves and sediment particles formed basis for an international research and development project comprising development of acoustic instrumentation for accurate local and in situ characterization of suspended sediments. The research project has been started recently under EEC's MAST programme [14]. In the research part of the project rather detailed theoretical models for acoustic (back)scattering by suspended sediment particles with different shapes, surface topography and materials will be developed and validated by experiments. Also nonlinear acoustic effects which might occur in suspensions of high concentrations will be studied. The influence of multiple scattering by randomly shaped, nonuniform size particles on the acoustic signal spectra will also be considered. This broad research programme should show a way to a better knowledge about acoustical, geophysical and transport qualities of suspended sediments.

\section{REFERENCES}

1. Dietz, R. S., J. Mar. Res., (1948), 7, 430-442.

2. Hay, A. E., J. Geoph. Res., (1983), 88 (c12), 7525-7542.

3. Ma, Y., Varadan, V. K., Varadan, V. V. and Bedford K. W., J. Acoust. Soc. Am., (1983), 74, 581-585.

4. Schaafsma, A. S., Acoustic Measurement of Concentration and Size of Sediment Particles Suspensions. In: Ultrasonics International 89, Conf. Proc., Butterworth (1989), 388-393.

5. van de Hulst, H. C., Light Scattering by Small Particles. Dover Publ. New York, (1981).

6. Hay, A. E., J. Acoust. Soc. Am., (1991), 90, 2055-2074.

7. Sheng, J and Hay, A. E., J. Acoust. Soc. Am., (1988), 83 , 598-610.

8. Thorne, P. D., J. Acoust. Soc. Am., (1992), 92, 978-986.

9. Bjørnø, L., Ultrasonics, (1986), 24, 254-259.

10. Apfel, R. E., J. Acoust. Soc. Am., (1983), 65, 1866.

11. Hagelberg, M. P., Holton, G. and Kao, S., J. Acoust. Soc. Am., (1967), 41, 564-567.

12. Wu, J. and Zhu, Z., J. Acoust. Soc. Am., (1991), 모, 2634-2639.

13. Bjørnø, L., Applied Scientific Research, (1982), 38, 291-296.

14. Schaafsma, A. S., Gyomar, D., van der Borck, G., Bjørn $\emptyset$, L., Kozhevnikova, I. N. and Person, R., Proceedings of Symposium of MAST Days and EUROMAR Market, 15-17 March 1993, M. Weydert and C. Fragakis (Ed.). Project reports, (1993), ㄹ, 606-611. 